\title{
Network externalities, complementarities, and invitations to enter
}

\author{
Nicholas Economides \\ Stern School of Business, New York Unirersity, New York. NY 10006. USA \\ Accepled 15 March 1995
}

\begin{abstract}
We discuss the incentive of an exclusive holder of a technology to share it with competitors in a market with network externalities. We assume that high expected sales increase the willingness to pay for the good. This is named the 'network effect'. At a stable fulfilled expectations equilibrium, where the actual sales are equal to the expected ones, it is shown that, if the network effect is sufficiently strong, a quantity leader has an incentive to invite entry and license his technology without charge. If the quantity leader has the opportunity to use lump sum license fees, he will invite a larger number of competitors. If no lump sum fees are allowed, the leader will charge a decreasing fee in the intensity of the network externality and will invite entry. In markets with very strong network externalities, the leader pays a subsidy to the invited followers. We also show that the results hold under uncertainty, and when the post-entry competition is Cournot.
\end{abstract}

IEL classification: $\mathrm{L} 1: \mathrm{D} 4$

Kevwords: Network externalities; Monopoly: Quantity leadership; Entry; Licensing

\section{Introduction}

In the battle for the establishment of technical standards, sponsorship of a 'standard' is of special significance. However, sponsorship is often insufficient to launch a new platform or 'standard' in an industry with significant network externalities. For example, on April 2, 1987, IBM came out with a new and more efficient bus architecture for personal computers called the Micro Channel Archi- 
tecture, or MCA. ' It was first announced as an exclusive technological advantage of IBM PS $/ 2$ personal computers. In the next 18 months, there were signs that the MCA 'standard' had significant difficulty in being accepted. Few other firms produced components that were compatible with MCA computers. In 1989 IBM announced that thereafter it would license the MCA bus without charge. In so doing, IBM invited other firms to compete with it in a product line in which IBM could have remained a monopolist. In another interesting example, some commentators have explained the demise and final withdrawal from the U.S. market of the Betamax VCR recording format by referring to the disregard of network effects by its sponsor, Sony. If Sony had freely licensed its Betamax technology to potential competitors, it might have created a sufficiently strong network and survived. In this paper we develop a model that explains the decision by a monopolist to invite competition and entry.

We focus on markets with significant network externalities. This means that the willingness to pay for a unit of a good sold in this comarket increases with the total number of units sold. ${ }^{2}$ We restrict expectations of sales to be equal to the actual sales, at equilibrium. We compare two regimes. In the first, there is only a single producer. This single firm is an innovator, and only it has the technology for the production of this good. In the second regime, the innovator provides the technology to other firms, so that there are $n$ active firms. The innovator is a quantity leader, and the other firms are quantity followers. ${ }^{3}$ It is shown that, when

I The internal bus defines the way in which information is transferred among the internal components of a computer, such as memory boards, video boards and microprocessors.

2 The positive consumption externalities, commonly called 'network externalities', arise from the existence and provision of complementary goods. Network externalities are a natural feature of networks (see Rohlfs (1974)). They also arise in many non-network markets where complementary goods are important, as in our two examples. In the MCA bus case, the complementary goods are the variety of add-on boards that get attached to the motherboard and communicate with it at the MCA specifications. These boards perform a variety of functions, such as video display support, termina] emulation, memory provision, etc., and users demand their availability at many quality levels. The early difficulty in the acceptance of the MCA bus by other-than-IBM personal computer manufacturers lead to inadequate provision of these complementary goods. This led to a further hesitation in the incorporation of the MCA bus in new PC 'IBM-clone' designs. In the Betamax case, the complementary good was pre-recorded movies in that format. Although unanticipated by Sony, large numbers of customers used VCRs to view pre-recorded commercially available material. Thus the existence and easy availability of large numbers of titles in a particular recording format became crucial. Originally aided by a longer duration recording capability and by a strong U.S. distribution network of many manufacturers, the competing VHS format became dominant in market share in the recorders/players market and in the number of titles of pre-recorded movies and their availability. Eventually, Sony withdrew from the U.S. market. See Economides and Salop (1992) for a discussion of pricing with complementaries, and Economides (1989), and Economides (1991) for the incentives of firms to produce compatible components. See Economides and White (1994) for a discussion of the economics of networks in the context of antitrust.

The particular quantity-leader/follower structure is not crucial for the results. which also hold in general terms for other oligopolistic models. 
the externalities are sufficiently strong, it pays for the monopolist to give away his technology to other firms that become its competitors.

The intuition for this 'paradox' is simple. Entry of competitors reduces prices and profits ceteris paribus. But the addition of their production to the size of the network shifts the inverse demand functions facing all network members, including the innovator (former monopolist). This allows the innovator to sell higher quantities and charge a higher price. Thus, if the externality is strong, the network effect overshadows the standard competitive effect of entry. As a result, the innovator is better off as one of $n$ oligopolistic firms rather than as a monopolist.

Why couldn't the monopolist produce a high quantity and create a large network effect without inviting competition? Our model is based on consumers expectations of network-wide sales that are fulfilled at equilibrium. Given a level of expected market-wide sales, firms choose their outputs in oligopolistic competition with each other. We require that the expected market output be realized at equilibrium. For any level of expected sales, a profit maximizing monopolist will choose a smaller output than total output in an industry with a larger number of firms. This implies that higher expectations of sales can only be fulfilled at equilibrium in a more competitive market with a larger number of participants. To be able to realize the benefits of a larger network effect, the innovator has to induce a higher market-wide output. Acting as a monopolist that uses only quantity as a strategic variable, the innovator is not able to commit credibly to produce a larger output (that would induce a higher willingness to pay through a larger network effect). "Even if the monopolist claimed that he would produce a large amount of output (to support at equilibrium a large network effect) he would not be believed because as a monopolist he has an incentive to reduce output for any given level of consumers expectations. Thus, the innovator creates the desirable network effect by inviting entry. The invitation to free entry supports the high expectations of sales, because the consumers know that a more competitive industry will have higher sales. By inviting entry and freely licensing, the innovator commits to a larger industry output for any level of initial expectations, and therefore to a larger equilibrium output at fulfilled expectations.

In an alternative reinterpretation of our model, abundance of varieties of a

\footnotetext{
This is shown for the quantity leadership game. and is extended to a simultaneous-acting quantity-setting game a-là-Cournot in Section 6.2.

This possibility was first raised in a similar model by Katz and Shapiro (1985. p. 431). They write. "It is interesting to note that the monopolists's profits may be lower than the profits of a duopolist in the 2 -active-firms symmetric equilibrium. In other words, a monopoly may benefit from entry. This unusual result follows from the fulfilled expectation condition: a monopolist will exploit his position with high prices and consumers know this. Thus. consumers expect a smaller network and are willing to pay less for the good. If the monopolist commit himself to higher sales, he would be better off. but this commitment is not credible so long as he is the sole producer".

- In this single-period game there is no possibility for the monopolist's price to be driven down according to the Coase conjecture.
} 
complementary product (e.g. boards for the MCA specification) results in lower prices and higher surplus for consumers. This increases the willingness to pay for MCA computers that are used in conjunction with the MCA add-on boards. The same result follows: high network externalities provide the incentive for an exclusive holder of a technology to freely license it. The difference between the two models is that the earlier is based on consumers expectations of sales and success of a new technology while in the latter the externality comes directly from sales of complementary goods.

When licensing is available, we show that, in industries with sufficiently strong network externalities, the monopolist has an incentive to subsidize the output of the competitors he invites to enter.

Our results are reminiscent of some results in the area of second-sourcing ${ }^{7}$ and licensing. Shepard (1987) shows that second-sourcing can enhance industry-wide demand through commitments to higher quality levels. Although quality is not explicitly a part of our model, our results have a common intuitive thread. A quality enhancement can be thought of as a good that is complementary to the basic commodity. Our paper shows how network externality effects are created through the market for complementary goods, and that if these effects are sufficiently strong there is an incentive to invite entry. Farrell and Gallini (1986) show that a monopolist may invite competitors with delay so as to commit to limiting future exploitation of consumers.

Although our results are established in quantity competition (in quantity leadership and in simultaneous Cournot), we expect that they will also hold under price competition if there is sufficient product differentiation. Nevertheless, we present no proof for this claim; it therefore remains to be proved by further research.

The structure of our analysis is the following. We start with an arbitrary consumers expectations on the size of sales, which results in an increased willingness to pay for the good which we call the 'network effect'. This is described in Section 2. Given an expected market size and the implied network effect, the leader and the $n-1$ followers play the standard quantity leadership game. In Section 3 the non-cooperative equilibrium production levels for all firms are computed as functions of the expected size of the market. In Section 4 we characterize the fulfilled expectations equilibrium, defined by the requirement that actual sales are equal to expected sales. In Section 5 we determine the incentives of the leader to invite entry and give away his proprietary technology. This is done through the comparison of fulfilled expectations equilibria with differing numbers

\footnotetext{
'Second-sourcing' occurs when a firm with a unique product but limited manufacturing capacity' allows other firms to produce its product under license. This is done to assure sufficient supply.

* See also Gallini (1984) and Crampes and Hollander (1993). Gallini and Wright (1990) discuss with problems of asymmetric information in licensing contracts.
} 
of active firms. Section 6 discusses two extensions of the basic model. The first extension introduces uncertainty. The second extension shows that the basic result of invitations to entry when there are strong network externalities holds when the post-entry competition is Cournot. In Section 7, we discuss the alternative interpretation of our model as describing a non-cooperative equilibrium across two complementary markets. Section 8 discusses licensing. Section 9 contains concluding remarks.

\section{The network effect}

Suppose that the expected size of sales in the market is $S$. Let the network externality function $f(S)$ measure the increase in the aggregate willingness to pay because of the existence of the network externality. In particular, in the presence of expected sales of size $S$, let the aggregate willingness to pay for quantity $Q$ increase from $P(Q ; 0)$ to

$$
P(Q: S) \equiv P(Q ; 0)+f(S) \text {. }
$$

Thus, we assume that the network externality enters additively and pushes the demand outward without changing its slope, that is, $\partial P(Q ; S) / \partial Q=\partial P(Q ; 0) / \partial Q$, independent of $S$. This means that the increase in willingness to pay because of the externality is the same for each unit sold, irrespective of its position on the demand curve. We use this particular functional form for simplicity, without a claim that in all network markets all consumers value the externality equally."

We place the following restrictions on $f(S)$.

1. $f(0)=0$. so that no expected sales produce no network externality. This is a normalization of the $f(S)$ function and it could have been done at a different level of $S$.

2. $f(S)$ is a differentiable function of $S$.

3. $f^{\prime}(S) \geq 0$, so that higher expected network sales do not produce a lower externality.

4. $\lim _{S \rightarrow x} \mathrm{~d} P(S, S)<0$, i.e., that eventually an equal increase in the expected and actual sales decreases the willingness to pay for the last unit. This rules out fulfilled expectations equilibria with infinite sales. Since $\lim _{S \rightarrow \times} \mathrm{d} P(S, S) / \mathrm{d} S$ $=\lim _{S \rightarrow x} \partial P(S ; S) / \partial Q+\lim _{S \rightarrow x} f^{\prime}(S)=\lim _{S \rightarrow \infty} \partial P(S ; 0) / \partial Q+\lim _{S \rightarrow \infty} f^{\prime}(S)$, the condition $\lim _{S \rightarrow \infty} \mathrm{d} P(S, S)<0$ is equivalent to $\lim _{S \rightarrow \infty} f^{\prime}(S)-$ $\lim _{S \rightarrow \infty} \partial P(S ; 0) / \partial Q$. We define $\lim _{S \rightarrow x} f^{\prime}(S) \equiv \theta$. For the particular demand function used below we have $\partial P(S ; 0) / \partial Q=-1$; then condition (iv) is equivalent to $\theta<1$.

\footnotetext{
In Economides and Himmelberg (1995). we explicitly allow for the opposite possibility. i.e.. that some consumers care less about the externality than others.
} 


\section{Quantity leadership equilibrium with given expectations}

Suppose that a market is described by inverse demand function ${ }^{10}$

$$
P(Q ; 0)=A-Q,
$$

so that, with the network externality, the inverse market demand is

$$
P(Q ; S)=A-Q+f(S) .
$$

In a quantity-setting game, let there be a leader and $n-1$ followers, so that

$$
Q=q_{i}+\sum_{i=1}^{n-1} q_{i}^{i},
$$

where $q_{r}$ and $q_{\mathrm{f}}^{i}$ are the quantities chosen by the leader and the $i$ th follower. Assume no costs. "The profit functions for the leader and followers are

$$
\Pi_{\ell}=q, P(Q, S), \quad \Pi_{\mathrm{f}}^{i}=q_{\mathrm{f}}^{i} P(Q, S), \quad i=1, \ldots, n-1 .
$$

Maximizing a follower's profits while keeping the production levels of all other firms constant, and then setting equal the production levels of all followers, results in

$$
q_{\mathrm{f}}^{i}=q_{\mathrm{f}}=\left[A+f(S)-q_{\ell}\right] / n .
$$

Substituting in the profit function of the leader and maximizing it results in the equilibrium production level for the leader:

$$
q,(S)=[A+f(S)] / 2 \text {. }
$$

Substituting back in the follower(s) best reply results in

$$
q_{\mathrm{f}}(S)=[A+f(S)] /(2 n) .
$$

Actual market-wide sales, market price, and realized profits are

$$
\begin{aligned}
& Q(S)=[A+f(S)](2 n-1) /(2 n), \quad P(S)=[A+f(S)] /(2 n), \\
& \Pi_{,}=[A+f(S)]^{2} /(4 n), \quad \Pi_{\mathrm{f}}=[A+f(S)]^{2} /\left(4 n^{2}\right) .
\end{aligned}
$$

Eq. (7)-(10) summarize the quantity leadership equilibrium for a given expectation of market size $S$. As expected, quantities, prices, and profits increase in sales expectations. Given any expectation $S$, prices and profits decrease in the number of active firms. In the next section, we restrict expectations to be fulfilled at the realized equilibrium.

\footnotetext{
Normalizing the size units, we set without loss of generality the coefficient of $Q$ to 1 .

11 The results are identical if constant marginal costs are assumed. Then 'prices' in the text are interpreted as differences between price and marginal cost. The general flavor of the results will not be lost if general cost functions are assumed.
} 


\section{Fulfilled expectations equilibrium}

At the overall equilibrium, the expectations have to be fulfilled. Thus, the level of the expected sales is the realized one. This defines the equilibrium level of expected (and realized) sales $S^{*}$ as the solution of

$$
S^{*}=Q\left(S^{*}\right) \Leftrightarrow S^{*}=\left[A+f\left(S^{*}\right)\right](2 n-1) /(2 n),
$$

where $Q(S)$ was substituted from Eq. (9). See Fig. I. $Q(S)$ can be thought of as a mapping of sales expectations into actual sales. Fulfilled expectations then define a fixed point $S^{*}$ of function $Q(S)$.

Lemma I. There exists at least one fulfilled expectations equilibrium level of sales.

Proof. By property (iv) of $f(S)$, eventually, for large $S>S_{1}, f^{\prime}(S)<1$; i.e., the marginal contribution of increased expectations of sales on the network externality is smaller than the increase in the size of the network. The slope of $Q(S)$ is $\mathrm{d} Q / \mathrm{d} S=f^{\prime}(S)(2 n-1) /(2 n)<f^{\prime}(S)$, and for these large $S>S_{1}, \mathrm{~d} Q / \mathrm{d} S<(2 n$ $-1) /(2 n)<1 . Q(S)$ starts (for $S=0$ ) at $Q(0)=A(2 n-1) /(2 n)>0$, i.e., above the $45^{\circ}$ line. Since eventually, for large $S$, the slope of $Q(S)$ is less than 1 , eventually, for large $S, Q(S)<S$. Therefore, since $Q(S)$ is continuous, it crosses the $45^{\circ}$ line at least once. QED.

Note in Eq. (9) that $Q(S)$ is a linear function of $f(S)$. Since $f(S)$ is relatively unrestricted. depending on the shape of $f(S)$, there can be many intersections of

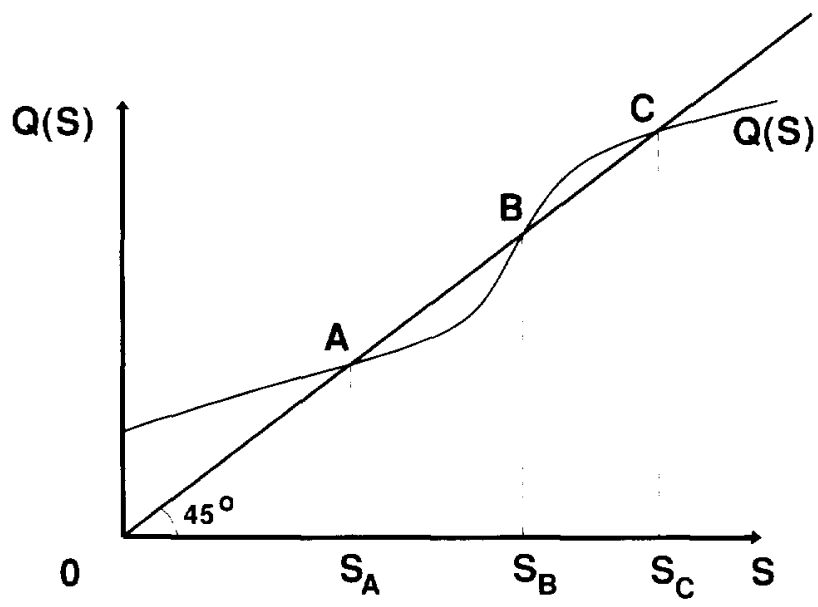

Fig. 1. Fulfilled expectations equilibria. 
$Q(S)$ with the $45^{\circ}$ line, each defining a fulfilled expectations equilibrium. In the networks externalities literature there has been wide use of concave and linear network externality functions. For such functions, the slope of $f(S)$ (and therefore of $Q(S))$ is a weakly decreasing function of $S$. Thus, there is no possibility of a second crossing of $Q(S)$ with the $45^{\circ}$ line and the fulfilled expectations equilibrium is unique.

Corollary 1 . If the network externality function is weakly concace, $f^{\prime \prime}(S) \leq 0$, then the fulfilled expectations equilibrium is unique.

The equilibrium is locally stable in expectations if and only if in the neighborhood of equilibrium $S^{*}$ the slope of $Q(S)$ is less than 1 ,

$$
\mathrm{d} Q\left(S^{*}\right) / \mathrm{d} S<1 \text {, i.e., } f^{\prime}\left(S^{*}\right)<2 n /(2 n-1) .
$$

In Fig. 1, equilibria $A$ and $C$ fulfill this condition, but equilibrium $B$ does not. Starting with expectations in the neighborhood of an unstable equilibrium but not exactly at the equilibrium value, there will be a tendency to move away from it. Given an unstable equilibrium, such as $\mathrm{B}$, with $Q^{\prime}(S)>1$, there always exists another stable equilibrium, such as $\mathrm{C}$ at a higher level of sales, $S_{\mathrm{C}}>S_{\mathrm{B}}$. This is because, as shown in the proof of Lemma 1, for large $S, Q^{\prime}(S)<1$, and eventually there will be a crossing of $Q(S)$ and the $45^{\circ}$ line with $Q^{\prime}(S)<1$. Thus, it may not be unreasonable to expect that an unstable equilibrium will be avoided in favor of a stable equilibrium at a higher $S$.

Lemma 2. A fulfilled expectations equilibrium is locally stable if and only if the marginal network externality is not too large, $f^{\prime}\left(S^{*}\right)<2 n /(2 n-1)$.

Corollan 2. For weakly concace network externality functions, $f^{\prime \prime}(S) \leq 0$, the unique equilibrium is globally stable.

Intuitively, we expect that an increase in market production for any given level of consumers expectations $S$ should support higher fulfilled expectations and
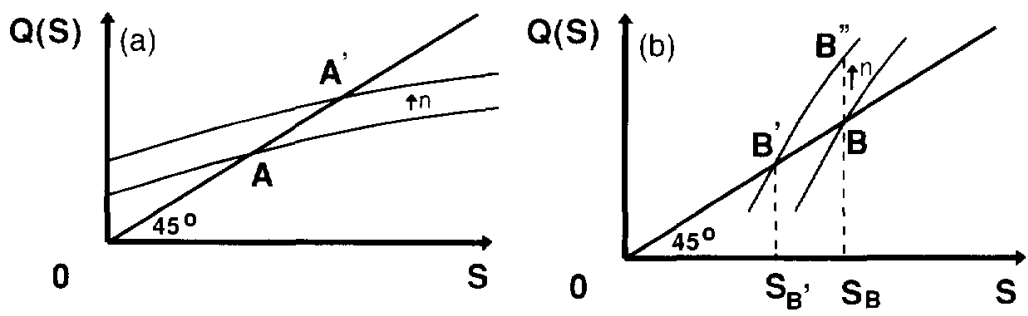

Fig. 2. Lpward shifts in $Q(S)$. 
therefore higher equilibrium production. This intuition is confirmed for stable equilibria. An increase in the number of firms $n$ increases the quantity produced for any consumers expectations $S$. That is, an increase in $n$ shifts up the $Q(S)$ function. As a result of the shift, $Q(S)$ intersects the $45^{\circ}$ line at a larger $S^{*}$ if the slope of $Q(S)$ is less than 1 (as in panel a of Fig. 2); conversely, the upward shift of $Q(S)$ results in a smaller $S^{*}$ if the slope of $Q(S)$ is larger than 1 (as in panel b of Fig. 2). Thus, increases in $n$ lead to increases in $S^{*}$ if and only if the fulfilled expectations equilibrium is locally stable.

Formally, from total differentiation of the fixed point condition (11) we derive $\mathrm{d} S^{*} / \mathrm{d} n$ :

$$
\mathrm{d} S^{*} / \mathrm{d} n=2 S^{*} /\left\{(2 n-1)\left[2 n-(2 n-1) f^{\prime}\left(S^{*}\right)\right]\right\} .
$$

$\mathrm{d} S^{*} / \mathrm{d} n>0$ is equivalent to the stability condition of the equilibrium in expectations $S{ }^{13}$

Proposition 1. Increases in the number of firms $n$ result in increased sales at the local fulfilled expectations equilibrium if and only the network externality at the margin is not too high. This is equiralent to the equilibrium being locally stable in expectations. ${ }^{14}$

Higher market-wide sales (induced by entry) imply higher sales for the leader. But prices could fall as a result of entry. It is a priori unclear if the leader should invite entry. This is examined in the next section.

\section{The leader's incentive to invite entry}

We are interested in the effects of increases in the number of competitors on the leader's profits. If we can show that the leader's profits increase in the number of

\footnotetext{
II $\left.\mathrm{d} S^{*} / \mathrm{d} n=-\left[\partial\left(Q\left(S^{*}\right)-S^{*}\right) / \mathrm{d} n\right] / \partial\left(Q\left(S^{*}\right)-S^{*}\right) / \partial S\right]=\left[A+f\left(S^{*}\right)\right] /(n[2 n-(2 n-$ 1) $\left.\left.f^{\prime}\left(S^{*}\right)\right]\right\}=2 S^{*} /\left\{(2 n-1)\left[2 n-(2 n-1) f^{\prime}\left(S^{*}\right)\right]\right\}$, where we substituted $A+f\left(S^{*}\right)=2 n S^{*} /(2 n-$ 1) from Eq. (11).

1.3 Note that. in cases of multiple equilibria. the upward shift of $Q(S)$ resulting from an increase in the number of competitors can also eliminate the low sales equilibria such as $A$.

${ }^{14}$ It may seem perverse. that in situations with high network externalities at the margin (which imply $Q^{\prime}(S)>1$ ), increases in the number of firms result in decreases in the size of $S^{*}$. The clue lies in the fact that $S^{*}$ is a fulfilled expectations equilibrium. Starting at equilibrium point B (Fig. 2b) where expected sales equal actual sales, $Q\left(S_{\mathrm{B}}\right)=S_{\mathrm{B}}$, an upward shift of $Q(S)$ (because of an increase in $n$ ) creates a gap between realized sales and expected sales (point $\mathrm{B}^{\prime \prime}$ ). Increasing $S$ above $S_{\mathrm{B}}$ would only lead to further disequilibrium because for every unit of increase in $S, Q(S)$ increases more. The only way to reach equilibrium locally is to reduce $S$ by going to point $\mathrm{B}^{\prime}$. A market size $S_{\mathrm{B}}$, smaller that $S_{\mathrm{B}}$ is the only level of fulfilled expectations (in the neighborhood of B) that is consistent with the shifted up $Q(S)$ function.
} 
competitors, then clearly it is in the interests of the leader to license its technology without charge and to invite entry. $\Pi *$,

Let the fulfilled expectations equilibrium profits ${ }^{15}$ of the leader be denoted by

$$
\Pi_{r}^{*}=\left[A+f\left(S^{*}\right)\right]^{2} /(4 n)=\left(S^{*}\right)^{2} n /(2 n-1)^{2} .
$$

As the number of firms increases, there are two opposite effects on the leader's profits. First, because the number of competitors increases, profits of the leader fall. This is the competitive effect. Second, as the number of competitors increases, the market can support larger expected sales as a fulfilled expectations equilibrium $S^{*}$. Increases in expected sales increase the leader's profits because they push up the industry demand through the expansion of the network. This is the network effect. These effects can be identified on $\Pi_{*}^{*}$ as follows:

Consider $\Pi_{i}^{*}$ as a continuous function ${ }^{16}$ of $n$ and $S^{*}$, where $S^{*}=S^{*}(n)$ depends on $n$ through the fulfilled expectations condition (11). ${ }^{17}$ Then the change in profits because of an increase in the number of market participants can be decomposed into the competitive effect and the network effect:

$$
\mathrm{d} \Pi_{,}^{*} / \mathrm{d} n=\partial \Pi_{,}^{*} / \partial n+\left(\partial \Pi_{*}^{*} / \partial S^{*}\right)\left(\mathrm{d} S^{*} / \mathrm{d} n\right)
$$

As expected, the direct effect of an increase in the number of firms is negative:

$$
\partial \Pi_{,}^{*} / \partial n=-(2 n+1)\left(S^{*}\right)^{2} /(2 n-1)^{3}<0 .
$$

Increases in expected sales increase profits:

$$
\partial \Pi_{,}^{*} / \partial S=2 n S^{*} /(2 n-1)^{2}>0,
$$

and from the discussion of the fulfilled expectations equilibrium in Section 4 we have

$$
\mathrm{d} S^{*} / \mathrm{d} n=2 S^{*} /\left\{(2 n-1)\left[2 n-(2 n-1) f^{\prime}\left(S^{*}\right)\right]\right\} .
$$

After substitution of all terms in Eq. (15) and simplification, the total effect of increases in $n$ on the leader's profits is

$$
\begin{aligned}
\mathrm{d} \Pi_{, *}^{*} / \mathrm{d} n= & \left(S^{*}\right)^{2}\left[(2 n+1) f^{\prime}\left(S^{*}\right)-2 n\right] \\
& /\left\{(2 n-1)^{2}\left[2 n-(2 n-1) f^{\prime}\left(S^{*}\right)\right]\right\} .
\end{aligned}
$$

Thus, the sign of the profits change in $n$ depends only on the slope $f^{\prime}\left(S^{*}\right)$ of the

\footnotetext{
15 From (1 1). $2 n S^{*} /(2 n-1)$ was substituted for $A+f\left(S^{*}\right)$.

in We use $n$ as a continuous variable and then evaluate the functions for integer $n$. Clearly, if $\mathrm{dI} I_{i} / \mathrm{dn}>0$, it follows that profits for a leader increase as the integer number of market participants increases.

17 Note that the formula for II, is valid even for monopoly with $n=1$ and no followers.
} 
network externality function. An increase in the number of active firms $n$ increases the leader's profits, $\mathrm{d} \Pi_{C}^{*} / \mathrm{d} n>0$, if and only if

$$
2 n /(2 n+1)<f^{\prime}\left(S^{*}\right)<2 n /(2 n-1) \text {. }
$$

For slopes $f^{\prime}\left(S^{*}\right)$ below $2 n /(2 n+1)$, the network effect is not sufficiently strong to overcome the competitive effect of an increase in $n$. Slopes $f^{\prime}\left(S^{*}\right)$ larger than $2 n /(2 n-1)$ imply an unstable equilibrium and a tendency to overshoot $S^{*}$. Since eventually (for large $S$ ) $f^{\prime}(S)<1$, for every unstable equilibrium $S_{\mathrm{B}}$, there will exist a stable equilibrium with larger $S, S_{\mathrm{C}}>S_{\mathrm{B}}$. It makes sense in this model for the leader to pick the equilibrium with the largest $S^{\star}$, which will be stable and therefore will fulfill the RHS of Eq. (19).

Proposition 2. An exclusice holder of a technology in a market with strong network externalities at the margin, $f^{\prime}\left(S^{*}\right)>2 n /(2 n+1)$, has an incentive to incite competitors to enter the industry and compete with him.

Note that the crucial parameter of the network externality function in these and the earlier results is $f^{\prime}(S)$, the marginal increase in the aggregate willingness to pay created by the expansion of the expected size of the network by one more unit. This is as it should be, since firms consider changes in strategic variables that affect total sales at the margin, which at equilibrium coincide with their expected level. Because of the importance of $f^{\prime}(S)$, we consider next a linear example with $f^{\prime}(S)=b$, a constant.

For example, let the network externality function be linear, $f(S)=b S, b<1$. From Corollaries 1 and 2, the fulfilled expectations equilibrium is unique and stable. The leader's profits at equilibrium increase in the number of firms for

$$
b>2 n /(2 n+1) \text {. }
$$

Therefore, given $b$, the leader should invite entry as long as condition (20) holds. Solving (20) with equality gives $n^{*}=b /[2(1-b)]$. $\Pi_{\succ}^{*}$ is maximized at $n^{*}$. Because this number is not in general an integer, the leader should compare his profits at $I\left[n^{*}\right]$ and $I\left[n^{*}+1\right]$ (where $I[\cdot]$ denotes the integer part function), and pick the number that corresponds to higher profits. Thus in an industry with very low fixed costs, the leader would like to invite entry but also restrict the number of firms that have free access to his technology.

\section{Extensions}

\subsection{Effects of uncertainty and diffuse preferences ${ }^{18}$}

We discuss next the market equilibrium and incentives to invite entry under uncertainty. We assume that the expectation of sales is stochastic with mean $\bar{S}$ and

\footnotetext{
${ }^{18}$ I thank Angelos Antzoulatos for his encouragement and help in developing this section.
} 
variance $\sigma^{2}$. Fulfilled expectations are defined by a rational expectations equilibrium where the expected mean sales are actualized, $\bar{S}=Q(\bar{S})$. In principle, one can impose fulfilled expectations on any number of moments of the distribution of expected sales. We follow the macroeconomic tradition of imposing fulfilled expectations only on the first moment of the distribution. ${ }^{19}$

We find that the invitation to entry result holds under uncertainty. We also find that increases in the variance of expectations decrease the fulfilled equilibrium sales, and invite entry. The reduction of the equilibrium sales is purely an adverse effect of uncertainty. Starting with a lower sales equilibrium, the incentive to invite entry is stronger.

Let $S$ be stochastic, distributed with density $h(S)$, mean $\bar{S}$ and variance $\sigma^{2}$. As before, $P(Q ; S)=A+f(S)-Q$. Firms maximize expected profits, $\Pi_{\ell}=$ $\mathrm{E}(q, P(Q ; S)), \Pi_{\mathrm{f}}^{i}=\mathrm{E}\left(q_{\mathrm{f}}^{i} P(Q ; S)\right)$, where $\mathrm{E}(\cdot)$ denotes the expectation function. Approximating $\Pi_{\ell}$ in a Taylor expansion we have

$$
\begin{aligned}
& \Pi_{,}=f\left[q_{\ell}[A-Q+f(S)] h(S) \mathrm{d} S\right. \\
& \simeq \int\left[q_{\curlywedge}\left[A-Q+f(\bar{S})+f^{\prime}(\bar{S})(S-\bar{S})+f^{\prime \prime}(\bar{S})(S-\bar{S})^{2} / 2\right] h(S) \mathrm{d} S\right. \\
& =q_{,}\left[A-Q+f(\bar{S})+f^{\prime \prime}(\bar{S}) \sigma^{2} / 2\right]
\end{aligned}
$$

Similarly,

$$
\Pi_{\mathrm{f}}^{i} \simeq q_{\mathrm{f}}^{i}\left[A-Q+f(\bar{S})+f^{\prime \prime}(\bar{S}) \sigma^{2} / 2\right] .
$$

Follower $i$ chooses

$$
q_{\mathrm{f}}^{i}=\left[A+f(\bar{S})+f^{\prime \prime}(\bar{S}) \sigma^{2} / 2-q_{\ell}\right] / n,
$$

and the leader chooses

$$
q_{i}=\left[A+f(\bar{S})+f^{\prime \prime}(\bar{S}) \sigma^{2} / 2\right] / 2,
$$

so that at market equilibrium,

$$
\begin{aligned}
& q_{\mathrm{f}}^{i}=\left[A+f(\bar{S})+f^{\prime \prime}(\bar{S}) \sigma^{2} / 2\right] /(2 n), \\
& Q(\bar{S})=\left[A+f(\bar{S})+f^{\prime \prime}(\bar{S}) \sigma^{2} / 2\right](2 n-1) /(2 n), \\
& \quad P=\left[A+f(\bar{S})+f^{\prime \prime}(\bar{S}) \sigma^{2} / 2\right] /(2 n), \\
& \Pi_{,}=\left[A+f(\bar{S})+f^{\prime \prime}(\bar{S}) \sigma^{2} / 2\right]^{2} /(4 n), \\
& \Pi_{\mathrm{f}}=\left[A+f(\bar{S})+f^{\prime \prime}(\bar{S}) \sigma^{2} / 2\right]^{2} /\left(4 n^{2}\right) .
\end{aligned}
$$

\footnotetext{
19 To impose fulfilled expectations up to the $M$ th moment, we would approximate $\Pi$, up to order $M+1$ in the Taylor expansion, and then equate the expected and actual values of the first $M$ moments.
} 
A rational expectations equilibrium is defined by actual equal to expected mean sales,

$$
\bar{S}=Q(\bar{S}) .
$$

Define $S^{*}=\bar{S}$ as the solution of this equation, i.e.,

$$
S^{*}=\left[A+f\left(S^{*}\right)+f^{\prime \prime}\left(S^{*}\right) \sigma^{2} / 2\right](2 n-1) /(2 n) .
$$

This equilibrium is meaningful when $S^{*}>0$. Assuming $f^{\prime \prime}<0$, a positive equilibrium size results when the variance is not too high, $\sigma^{2}>2[A+$ $\left.f\left(S^{*}\right)\right] /\left[-f^{\prime \prime}\left(S^{*}\right)\right]$. Intuitively, when there is extreme uncertainty in the expectations of the consumers, both types of firms will not provide the good because they expect that positive sales will not be realized at equilibrium.

A concave network externality function implies decreasing $q_{,}$and $q_{1}$ in $\sigma^{2}$. Therefore, with $f^{\prime \prime}<0$, the rational expectations equilibrium $S^{*}$ is decreasing in variance $\sigma^{2}$. It follows that equilibrium sales and profits are smaller under uncertainty than under certainty.

Proposition 3. For concave network externalities functions, the rational expectations equilibrium production decreases in the cariance of the expectations.

We now consider the effect of inviting entry, i.e., of increasing $n$. The equilibrium profits at the rational expectations equilibrium are

$$
\begin{aligned}
\Pi_{r^{*}}^{*}=[A+ & \left.f\left(S^{*}\right)+f^{\prime \prime}\left(S^{*}\right) \sigma^{2} / 2\right]^{2} /(4 n)=\left(S^{*}\right)^{2} n /(2 n-1)^{2} . \\
\mathrm{d} \Pi_{,} / \mathrm{d} n= & \partial \Pi_{r^{*}} / \partial n+\left(\partial \Pi^{*} / \partial S^{*}\right)\left(\mathrm{d} S^{*} / \mathrm{d} n\right) \\
= & \left(S^{*}\right)^{2}\left\{(2 n+1)\left[f^{\prime \prime}\left(S^{*}\right)+f^{\prime \prime \prime}\left(S^{*}\right) \sigma^{2} / 2\right]-2 n\right\} \\
& /\left\{(2 n-1)^{2}\left[2 n-(2 n-1)\left[f^{\prime}\left(S^{*}\right)+f^{\prime \prime \prime}\left(S^{*}\right) \sigma^{2} / 2\right]\right]\right\} . \\
\mathrm{d} \Pi_{r^{*} / \mathrm{d} n>0} \Leftrightarrow & 2 n /(2 n+1)<f^{\prime}\left(S^{*}\right) \\
& +f^{\prime \prime \prime}\left(S^{*}\right) \sigma^{2} / 2<2 n /(2 n-1) .
\end{aligned}
$$

We expect that the criterion $f^{\prime}\left(S^{*}\right)+f^{\prime \prime \prime}\left(S^{*}\right) \sigma^{2} / 2$ will increase with the degree of uncertainty as measured by the variance $\sigma^{2}$. An increase in $\sigma^{2}$ causes $S^{\times}$to be lower, as we have seen. This increases $f^{\prime}\left(S^{*}\right)$ because of the concavity of $f$. Also many network externality functions, such as $f(S)=\log (S)$, have a positive third derivative. Then the positive effects of increases in $\sigma^{2}$ on the criterion function are accentuated. Formally, $\mathrm{d}\left(f^{\prime}+f^{\prime \prime \prime} \sigma^{2} / 2\right) / \mathrm{d} \sigma^{2}=f^{\prime \prime \prime} / 2+\left(f^{\prime \prime}\right.$ $\left.+f^{\prime \prime \prime} \sigma^{2} / 2\right)\left(\mathrm{d} S^{*} / \mathrm{d} \sigma^{2}\right)$, which is positive if $f^{\prime \prime}<0, f^{\prime \prime \prime} \geq 0, f^{\prime \prime \prime \prime} \leq 0$. Therefore the incentive to invite entry increases with uncertainty, and a monopolist facing a market with diffuse expectations has stronger incentives to invite entry. Intuitively, 
in the presence of uncertainty, the total market output is more precisely predictable in the presence of $n$ firms than with only the monopolist present. Thus, under uncertainty, the presence of entrants has a law-of-large-numbers stabilizing effect on expected output, and this is seen favorably by the market.

Proposition 4. The incentive to incite entry increases with the lariance of the expectations, provided that the first four derivatives of the network externality function alternate in sign: $f^{\prime}>0, f^{\prime \prime}<0, f^{\prime \prime \prime} \geq 0, f^{\prime \prime \prime \prime} \leq 0 .{ }^{20}$

\subsection{Cournot oligopoly}

To stress that the results hold not only for the particular market structure employed this far (quantity leadership), we briefly discuss the symmetric Cournot market structure, and confirm that, with sufficiently strong network externality at the margin, a monopolist will invite entrants.

Here we discuss the decision to invite entry by a monopolist if after entry the resulting competition will be Cournot oligopoly. Starting with industry demand function $P(Q ; S)=A+f(S)-Q$, firm $i$ maximizes $\Pi_{i}=q_{i} P(Q ; S)$ by choosing $q_{i}$, where $Q=q_{i}+\sum_{j \neq i}^{n} q_{j}$. The first-order condition of firm $i$ is

$$
\partial \Pi_{i} / \partial q_{i}=A+f(S)-2 q_{i}-\sum_{j \neq i}^{n} q_{j}=0 .
$$

The implied symmetric market equilibrium is,

$$
\begin{aligned}
& q_{i}=(A+f(S)) /(n+1), Q=n(A+f(S)) /(n+1), \\
& P=(A+f(S)) /(n+1), \Pi_{i}=(A+f(S))^{2} /(n+1)^{2} .
\end{aligned}
$$

At fulfilled expectations,

$$
S^{*}=Q\left(S^{*}\right) \Leftrightarrow S^{*}=n\left[A+f\left(S^{*}\right)\right] /(n+1) .
$$

An increase in the number of competitors increases market production iff

$$
\mathrm{d} S^{*} / \mathrm{d} n=S^{*} /\left\{n\left[n+1-n f^{\prime}\left(S^{*}\right)\right]\right\}>0 \Leftrightarrow f^{\prime}\left(S^{*}\right)<(n+1) / n \text {. }
$$

This condition is equivalent to local stability of the fulfilled expectations equilibrium.

The equilibrium profits of a firm at an $n$-firm fulfilled expectations equilibrium are

$$
\Pi_{i}^{*}=\left(A+f\left(S^{*}\right)\right)^{2} /(n+1)^{2}=\left(S^{*} / n\right)^{2} .
$$

\footnotetext{
20 These conditions are fulfilled by many network externality functions, including the logarithm of sales. $f(S)=\log (S)$.
} 
Profits of the innovator increase as a result of the introduction of competitors if

$$
\mathrm{d} \Pi_{i}^{*} / \mathrm{d} n=\partial \Pi_{i}^{*} / \partial n+\left(\partial \Pi_{i}^{*} / \partial S^{*}\right)\left(\mathrm{d} S^{*} / \mathrm{d} n\right)>0 .
$$

By substitution and simplification we find

$$
\mathrm{d} \Pi_{i}^{*} / \mathrm{d} n=S^{* 2}\left[n f^{\prime}\left(S^{*}\right)-(n-1)\right] /\left[n^{3}\left(n+1-n f^{\prime}\left(S^{*}\right)\right)\right] .
$$

Therefore,

$$
\mathrm{d} \Pi_{i}^{*} / \mathrm{d} n>0 \Leftrightarrow(n-1) / n<f^{\prime}\left(S^{*}\right)<(n+1) / n .
$$

Proposition 5. An exclusive holder of a technology has an incentice to invite entry if there are strong network externalities, $f^{\prime}\left(S^{*}\right)>(n-1) / n$, and the after-entry market structure is Cournot oligopoly.

\section{An alternative interpretation of the basic model}

This far, our basic model was assuming the existence of a network externality without a detailed analysis of the source of the externality. Next we present a different interpretation of the basic model in the context of two industries that produce complementary goods. This interpretation also helps justify the existence of the externalities.

Let there be two industries that produce complementary goods that are combined in 1:1 ratio in consumption. Suppose that one firm is the exclusive holder of the rights to the technology in industry 1 , but there is free entry in industry 2 . The monopolist in industry 1 may invite $n_{1}-1 \geq 0$ competitors. When production levels in industries 1 and 2 are $Q_{1}$ and $Q_{2}$, the willingness to pay for product 1 is

$$
P\left(Q_{1} ; Q_{2}\right)=A-Q_{1}+f\left(Q_{2}\right) \text {. }
$$

In this context, $Q_{1}$ plays the role of $Q$, and $Q_{2}$ plays the role of $S$ of our previous discussion. Why is the willingness to pay for product 1 increasing in the production level of product 2 , i.e., where is the source of the network externality? Higher production $Q_{2}$ implies a larger number of varieties of product 2 and a lower price for them. Thus, with higher $Q_{2}$, the surplus realized by consumers of product 2 is higher. Since products 1 and 2 are complementary, higher surplus generates a higher willingness to pay for product 1 . This is captured by $f\left(Q_{2}\right)$. Thus, the network externality arises out of mutual positive feedbacks in a pair of markets for complementary goods.

To understand the structure of the mutually complementary markets, we present a simple example. Suppose that there are $n_{2}$ symmetrically located differentiated products on a circumference as in Salop (1979). Let consumers be distributed uniformly with density $\mu$ according to their most preferred variety, have a disutility of distance equal to 1 , and a reservation price of $R$ which is sufficiently 


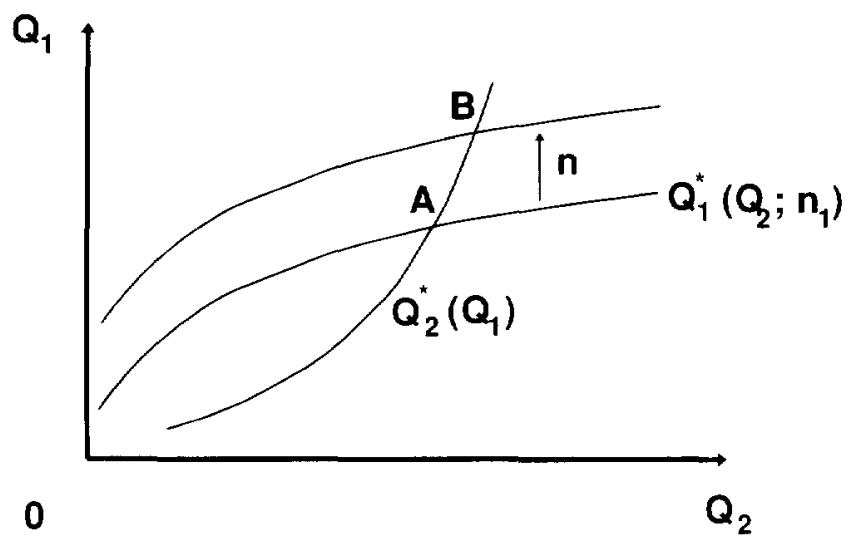

Fig. 3. Complementary markets with feedbacks.

large so that all consumers buy a differentiated good. ${ }^{21}$ The symmetric equilibrium price is $p^{*}\left(n_{2}\right)=1 / n_{2}$, and profits are $\Pi\left(n_{2}\right)=\mu / n_{2}^{2}-F$. With free entry, $\Pi\left(n_{2}\right)=0$; therefore there will be $n_{2}^{*}=\sqrt{ }(\mu / F)$ active firms. The average benefit of a consumer from the consumption of one unit of product 2 is then

$$
R-\left[p^{*}\left(n_{2}^{*}\right)+1 /\left(4 n_{2}^{*}\right)\right]=R-(5 / 4) /(F / \mu) .
$$

Interpreting $\mu$ as $Q_{2}$ (since every consumer on the circumference buys a differentiated good), the average benefit to a consumer when there are $Q_{2}$ sales in market 2 is $f\left(Q_{2}\right)=R-(5 / 4)_{V}\left(F / Q_{2}\right)$. Since products 1 and 2 are consumed in $1: 1$ ratio, this average benefit should be added to the willingness to pay of consumers for good 1 . The network externality $f\left(Q_{2}\right)$ is increasing in $Q_{2}$ because a high level of production in industry 2 implies a larger number of varieties $n_{2}$ and a higher degree of competition.

Firms play an oligopoly game in market 1 , taking $Q_{2}$ as given. Let the resulting equilibrium output be $Q_{1}^{*}\left(Q_{2} ; n_{1}\right)$. This is a direct reinterpretation of $Q(S ; n)$. See Fig. 3. Firms in market 2 take $Q_{1}$ as given. Let equilibrium output in market 2 be $Q_{2}^{*}\left(Q_{1}\right)$. In the expectations model, we used $S^{*}(Q)=Q$, i.e., $Q_{2}^{*}\left(Q_{1}\right)=Q_{1}$, and this applies well in a model where the two types of products are consumed in 1:1 ratio, as in our circumference example. In general, when goods 1 and 2 are not consumed in a $1: 1$ ratio, $Q_{2}^{*}\left(Q_{1}\right)$ will not be the identity function; it is shown in Fig. 3 as an upward-sloping curve.

Equilibrium across markets defines $Q_{1}^{* *}, Q_{2}^{* *}$ as the intersection of $Q_{1}^{*}\left(Q_{2} ; n_{1}\right)$ and $Q_{2}^{*}\left(Q_{1}\right)$. Increasing the number of firms $n_{1}$ shifts $Q_{1}^{*}\left(Q_{2} ; n_{1}\right)$ to the right. The effect of the increase of $n_{1}$ on equilibrium output in industry 1 is

\footnotetext{
2 We could also allow the reservation price $R$ in industry 2 to vary in $Q_{1}$ without changing the result.
} 
$\mathrm{d} Q_{1}^{* *} / \mathrm{d} n_{1}=\left(\mathrm{d} Q_{1}^{*} / \mathrm{d} n_{1}\right) /\left[1-\left(\mathrm{d} Q_{1}^{*} / \mathrm{d} Q_{2}\right)\left(\mathrm{d} Q_{2}^{*} / \mathrm{d} Q_{1}\right)\right]$, which is positive if the equilibrium is stable $\left(1>\left(\mathrm{d} Q_{1}^{*} / \mathrm{d} Q_{2}\right)\left(\mathrm{d} Q_{2}^{*} / \mathrm{d} Q_{1}\right)\right)$ provided that an increase of the number of active firms in industry 1 results in an increase of its equilibrium output, i.e., $\mathrm{d} Q_{1}^{*} / \mathrm{d} n_{1}>0$. See Fig. 3 .

The effect of increases in $n_{1}$ on the profits of the original monopolist depends on the particulars of the oligopolistic interaction in markets 1 and 2, as well as on the degree of complementarity between the two markets. As we have seen, if goods 1 and 2 are consumed in 1:1 ratio, this model of interaction across complementary markets is an exact reinterpretation of the expectations model. In that case, all propositions of the expectations model can be directly reinterpreted for complementary goods model. In more general settings of variable degrees of complementarity between markets, one still expects results of the same flavor, i.e., strong network externalities on the margin leading to invitations to enter.

\section{Licensing}

\subsection{Lump sum fees}

We have shown that it is beneficial to the leader to invite entry while charging a zero licensing fee, but that he may want to restrict the number of firms to which he freely gives his innovation. One way to achieve the latter without creating incentives for firms to cut output is to put licensing fees per firm. Suppose the innovator imposes a marginal fee of $k$ per unit of output of an invited firm, and a lump sum fee of $\lambda$ per invited firm. A follower's profits,

$$
\Pi_{\mathrm{f}}^{\mathrm{L}}=q_{\mathrm{f}}\left(S^{*}\right)\left(P\left(S^{*}\right)-k\right)-\lambda .
$$

will be set to zero as the licensing fee will be set so as to absorb all profits of followers. Then the leader's profits are 22

$$
\begin{aligned}
\Pi_{\ell}^{\prime} & =\Pi_{i}^{*}+(n-1)\left[q_{\mathrm{t}}\left(S^{*}\right)\left(P\left(S^{*}\right)-k\right)+k q_{i}\left(S^{*}\right)\right] \\
& =\Pi_{i}^{*}+(n-1)\left[A+f\left(S^{*}\right)\right]^{2} /\left(4 n^{2}\right)=\Pi_{;}^{*}[(2 n-1) / n]
\end{aligned}
$$

Note that, because all profits are absorbed through the lump sum fee, the marginal fee is immaterial.

The marginal effect of an increase in $n$ on the leader's profits (comparable to Eq. (15)) is

$$
\begin{aligned}
\mathrm{d} \Pi_{r}^{\mathrm{L}} / \mathrm{d} n & =\partial \Pi^{\mathrm{L}} / \partial n+\left(\partial \Pi_{,}^{\mathrm{L}} / \partial S\right)\left(\mathrm{d} S^{*} / \mathrm{d} n\right) \\
& =\Pi_{,}^{*} / n^{2}+\left(\mathrm{d} \Pi_{,}^{*} / \mathrm{d} n\right)[(2 n-1) / n]>\mathrm{d} \Pi_{,}^{*} / \mathrm{d} n .
\end{aligned}
$$

\footnotetext{
22 We find the last expression of profits in Eq. (43) from Eq. (11) evaluated at $S^{*}$.
} 
Therefore, with lump sum licensing fees the leader prefers an even larger number of competitors $n^{\mathrm{L} *}>n^{*}$. The licensing fee $\lambda^{*}$ can be increased abruptly at $n^{\mathrm{L} *}$, the optimal number of competitors from the leader's point of view, to thwart further entry.

Proposition 6. An exclusive holder of a technology in a market with strong network externalities at the margin will invite a larger number of competitors to enter if he can charge lump sum licensing fees.

\subsection{Marginal licensing fees}

Often lump sum fees are unfeasible. Thus, we consider licensing with fees per unit sold for linear network externality functions, $f(S)=b S$. Let the leader collect a licensing fee of $k$ per unit of output of the followers. The profit functions for the leader and the followers are now

$$
\Pi_{f}=q_{f} P(Q, S)+k(Q-q,), \quad \Pi_{\mathrm{f}}=q_{\mathrm{f}}^{i}[P(Q, S)-k], \quad i=1, \ldots, n-1 .
$$

Given $S$ and $k$, the equilibrium in the leader-follower game is

$$
\begin{aligned}
& q,(S)=[A+b S] / 2, \quad q_{\mathrm{f}}(S)=[A+b S-2 k] /(2 n), \\
& Q(S)=[(A+b S)(2 n-1)-2 k(n-1)] /(2 n), \\
& P(S)=[A+b S+2 k(n-1)] /(2 n), \\
& \Pi_{f}=(A+b S)^{2} / 4-(n-1)(A+b s-2 k)^{2} /(4 n), \\
& \Pi_{\mathrm{f}}=[(A+b S-2 k) /(2 n)]^{2} .
\end{aligned}
$$

Imposing self-fulfilled sales expectations, i.e., $S^{*}=Q\left(S^{*}\right)$, determines the fulfilled equilibrium sales:

$$
Q\left(S^{*}\right)=[A(2 n-1)-2 k(n-1)] /[2 n-b(2 n-1)] .
$$

This equilibrium exists and is unique and globally stable provided that

$$
\mathrm{d} Q / \mathrm{d} S<1, \Leftrightarrow b<2 n /(2 n-1) .
$$

The individual quantities, price and profits at the equilibrium are

$$
\begin{aligned}
& q,\left(S^{*}\right)=[n A-b k(n-1)] /[2 n-b(2 n-1)], \\
& \quad q_{\mathrm{f}}\left(S^{*}\right)=[A-(2-b) k] /[2 n-b(2 n-1)], \\
& P\left(S^{*}\right)=[A+2 k(n-1)(1-b) /[2 n-b(2 n-1)], \\
& \Pi_{r}\left(S^{*}\right)=q_{,}\left(S^{*}\right) P\left(S^{*}\right)+k(n-1) q_{\mathrm{f}}\left(S^{*}\right), \\
& \quad \Pi_{\mathrm{f}}\left(S^{*}\right)=q_{\mathrm{f}}\left(S^{*}\right)\left[P\left(S^{*}\right)-k\right] .
\end{aligned}
$$


Equilibrium production decreases in the size of the licensing fee

$$
\mathrm{d} Q\left(S^{*}\right) / \mathrm{d} k=-2(n-1) /[2 n-b(2 n-1)]<0 .
$$

Equilibrium price increases in the size of the licensing fee if the network effect is weak, but decreases in the size of the licensing fee if the network effect is strong:

$$
\mathrm{d} P\left(S^{*}\right) / \mathrm{d} k=2(n-1)(1-b) /[2 n-b(2 n-1)] ; \mathrm{d} P\left(S^{*}\right) / \mathrm{d} k>0 \Leftrightarrow b<1 .
$$

The leader chooses the marginal license fee to maximize $\Pi,\left(S^{*}\right)$. He solves

$$
\begin{aligned}
\mathrm{d} \Pi\left(S^{*}\right) / \mathrm{d} k= & 2(n-1)\left[2 A n(1-b)-k\left(b^{2}+4 n(1-b)\right]\right. \\
& /[2 n-b(2 n-1)]^{2}=0,
\end{aligned}
$$

and chooses the optimal license fee

$$
k^{*}=n A(1-b) /\left(b^{2}-4 b n+4 n\right) .
$$

Because of second-order conditions, ${ }^{23}$ the licensing problem is well-defined only the denominator of $k^{*}$ is positive, i.e., $b^{2}-4 b n+4 n>0$. The optimal fee decreases ${ }^{24}$ in $b$ and is positive for $0 \leq b<1$ and negative for $1<b<b_{2}=2$ (n $\left.-[n(n-1)]^{1 / 2}\right\}$, the smaller of the roots of the denominator of $k^{*}$. Note that the signs of $k^{*}$ and $\mathrm{d} P\left(S^{*}\right) / \mathrm{d} k$ coincide. Thus, for weak externalities it is optimal for the leader to charge a positive fee, and this increases the market price. For strong network externalities, the leader gives a subsidy, and this increases the equilibrium price above its level with no subsidy. The licensing fee increases in the number of competitors $n$ for $b<1$ (while the fee is positive). For $b>1$ the optimal subsidy increases in $n .^{25}$

Proposition 7. The leader charges a positice licensing fee in a market with weak network externalities. Conversely, in a market with strong network externalities, the leader is willing to give a subsidy to his competitors to encourage higher production. In the case when the licensing fee chosen by the innocator is positive. the fee also increases with the number of competitors. When the leader chooses to subsidize the followers, his subsidy increases with the number of his competitors.

These results are rather intuitive. In a market with small network externalities, the result is the same as in a market with no externalities, i.e., the leader charges a positive licensing fee. Since in this case the benefit from the externality is small, the leader increases his profit by restricting at the margin the level of output of his

\footnotetext{
$23 \quad \mathrm{~d}^{2} I I,\left(S^{*}\right) / \mathrm{d} k^{2}=-2(n-1)\left(b^{2}+4 n(1-b)\right] /[2 n-b(2 n-1)]^{2}<0$ iff $\left(b^{2}+4 n(1-b)>0\right.$. The roots of this are $b_{1}=2\left\{n+[n(n-1)]^{1 / 2}\right\}, b_{2}=2\left\{n-[n(n-1)]^{1,2}\right\}$. For $\left(b^{2}+4 n(1-b)>0\right.$ the binding condition is $b<b_{2}$.

$2+\mathrm{d} k^{*} / \mathrm{d} b=2 n b A(b-2) /\left(b^{2}-4 b n+4 n\right)^{2}<0$.

$25 \mathrm{~d} k^{*} / \mathrm{d} n=A b^{2}(1-b) /\left(b^{2}-4 b n+4 n\right)^{2}$.
} 
competitors through a positive licensing fee. This fee is higher if there are more competitors, to compensate for the higher output. Conversely, when the network externalities are strong, the leader gives a subsidy to his competitors to encourage increased production and greater network effects from which he will benefit. In this case the optimal subsidy increases in the number of competitors to create the strongest externality.

The profits of the leader who invites $n$ competitors and uses the optimal marginal licensing fee are

$$
\Pi_{r}^{\mathrm{M}}=n A^{2} /\left(b^{2}-4 b n+4 n\right) .
$$

They are an increasing function of $n .{ }^{26}$ We have already shown that the optimal licensing fee is also increasing in $n$. Thus, for small network externalities, to generate the same externality (from the same amount of industry output) it is more profitable for the monopolist to invite many competitors and collect high royalties from them rather than invite few and collect low royalties. This is because the monopolist collects higher total royalties in the former case.

Proposition 8. When the leader uses marginal licensing fees, profits increase in the number of competitors. Thus, the leader has an incentive to invite competitors.

Note that it is to the benefit of the leader to invite competitors, both when the license fee is positive and again when it is negative. The intuitive reasons are different in each case. When network externalities are strong, the leader invites competitors, and provides them with a subsidy to enjoy the strong network effects. When the network externalities are relatively weak, the first objective of the leader is to collect the licensing fees; cultivating the network effects is secondary. Of course, in both cases, optimal marginal fee licensing is superior to free licensing, so that,

$$
\Pi_{f^{\mathrm{M}}}^{\mathrm{P}}>\Pi_{f^{*}}
$$

It may be infeasible to subsidize direct competitors at significant levels that are required in the case of strong network externalities. Subsidization of direct (horizontal) competitors may raise eycbrows even in today's liberal antitrust climate. Thus, the upper limit in the amount of the subsidy imposed by the legal environment may implicitly determine the number of the firms that the leader will invite.

26. $\mathrm{d} I, / \mathrm{d} n=A^{2} b^{2} /\left(b^{2}-4 b n+4 n\right)>0$. 


\section{Concluding remarks}

We have found that in a market with strong network externalities, if there are no other means of commitment to high production (such as binding contractual commitments or vertical integration), an innovator quantity leader has incentives to license his technology freely to competitors. This seeming paradox occurs because the leader benefits from the increase in the size of the network that comes with the introduction of competitors and the increase in competition. The expansion of output required for the creation of a large network cannot be done in the absence of competitors. The innovator-monopolist cannot credibly commit himself to create a large network (and reap its benefits) because given any level of consumers' expectations of sales, the monopolist has an incentive to produce a relatively low output. Nevertheless, the innovator can use the fact that a more competitive market will result in a higher output (for any given expectations). By inviting competition, the innovator commits to an expanded amount of market output for any given expectations. Thus, the innovator credibly sustains the expectation of a high production by inviting competition, and thereby creates the desired large network effect. These results also hold in the presence of uncertainty and under different conditions of oligopolistic competition.

We have also shown that the expectations model is formally equivalent to a model of strategic interaction between two complementary markets. In this framework, the size of sales in industry 2 affects positively the surplus realized in industry 2. This in turn affects positively the willingness to pay for the complementary good 1. Because of the formal equivalence, all results can be reinterpreted in the framework of two complementary markets.

The innovator acting as a quantity leader does even better and invites more competitors if he can charge lump sum licensing fees. If the leader can charge only marginal licensing fees, his optimal licensing fee will be positive for markets with weak network externalities, and negative (i.e.. a subsidy) when the externalities are strong. For both weak or strong network externalities, the leader invites entry as well, and has higher profits than when licensing was free.

There are a number of dimensions in which this research can be extended. First, it can be used as a basis for the construction of a model of competing networks that also compete in acquiring members. In such an endeavor, a discussion of non-cooperative coalition formation and stability as in Economides (1988) and more recently in $\mathrm{Yi}$ and Shin (1992) is essential. ${ }^{27}$ Second, incorporating both vertically and horizontally differentiated products in the industry exhibiting the externality is desirable. There are many industries (e.g. VCR players) where the externality brought to a network (firms that adhere to the same technical standard) by a consumer of a low quality good could be as large as the externality created by

See also Donsimoni et al. (1986). 
a consumer of a high quality good. For example, it could be that the propensity to rent pre-recorded movies is equal for consumers that buy high quality VCRs as for those who buy low quality VCRs. In such cases we expect to observe subsidization of the low quality buyers and producers by the high quality producers. For example, subsidization of low quality producers can occur through the use of differential licensing fees. Seen in this context, the cross subsidization commonly observed in networks may not be undesirable.

\section{Acknowledgements}

I thank Angelos Antzoulatos, Bob Dansby, Rob Masson, Dennis Mueller, Joe Farrell, Frank Fisher, Bill Greene, Charlie Himmelberg, Manfred Holler, Paul Joskow, Bruno Jullien, Barbara Katz, Michael Katz, David Salant, Jacques Thisse, Richard Schmalensee, Ralf Winkler, Glenn Woroch, an anonymous referee, the participants at seminars at C.O.R.E, E.N.S.A.E, M.I.T., the University of Maryland, the Private Networks and Public Objectives Conference of the Columbia Institute for Tele-information, and the Eastern Economic Association Meetings for useful suggestions.

\section{References}

Crampes. Claude and Abraham Hollander. 1993, Umbrella pricing to attract early entry, Economica 60, $465-474$.

Donsimoni, Marie-Paule. Nicholas Economides, and Heraclis Polemarchakis. 1986, Stable cartels, International Economic Review 22, no. 2. 317-327.

Economides, Nicholas, 1988, Equilibrium coalition structures, Discussion paper no. 273 (Department of Economics, Columbia University, New York)

Economides, Nicholas, 1989, Desirability of compatibility in the absence of network externalities, American Economic Review 78, no. 1, 108-121.

Economides, Nicholas, 1991, Compatibility and the creation of shared networks, In: Margaret Guerrin-Calvert and Steven Wildman, eds.. Electronic services networks: A business and public policy challenge (Praeger Publishing Inc., New York).

Economides, Nicholas and Charles Himmelberg, 1995. Critical mass and network evolution in telecommunications, In: Gerard Brock, ed.. Toward a competitive telecommunications industry: Selected papers from the 1994 Telecommunications Policy Research Conference.

Economides, Nicholas and Steven C. Salop, 1992. Competition and integration among complements, and network market structure, Journal of Industrial Economics XL, no. I.

Economides, Nicholas and Lawrence J. White, 1994, Networks and Compatibility: Implications for Antitrust, European Economic Review 38, 651-662.

Farrell. Joseph and Nancy Gallini. 1986, Second-sourcing as a commitment: Monopoly incentives to attract competition, Quarterly Journal of Economics 103, 673-694.

Gallini, Nancy, 1984, Deterrence by market sharing: A strategic incentive for licensing, American Economic Review 74, no. 5, 931-941.

Gallini, Nancy and Brian Wright, 1990, Technology transfer under asymmetric information. Rand Journal of Economics 21, no. 1,147-160. 
Katz. Michael and Carl Shapiro, 1985, Network externalities, competition and compatibility, American Economic Review 75. no. 3. 424-440.

Rohlfs, Jeffrey. 1974. A theory of interdependent demand for a communications service, Bell Journal of Economics 5, 16-37.

Salop. Steven C.. 1979, Monopolistic Competition with outside Goods, Bell Journal of Economics 10 , 141-156.

Shepard. Andrea. 1987. Licensing to enhance demand for new technologies, Rand Journal of Economics 18, no. 3, 360-368.

Yi. Sang-Seung and Hyukseung Shin, 1992a. Endogenous formation of coalitions. Part I: Theory, Mimeo. 